\title{
Mapping the landscape of human dopamine D2/3 receptors with $\left[{ }^{11} \mathrm{C}\right]$ raclopride
}

\author{
Goran Papenberg ${ }^{1}\left(\right.$ Lars Jonasson $^{2,3} \cdot$ Nina Karalija $^{2,4} \cdot$ Jarkko Johansson $^{2,4} \cdot$ Ylva Köhncke $^{5} \cdot$ Alireza Salami $^{1,2,3,6}$. \\ Micael Andersson ${ }^{2,3} \cdot$ Jan Axelsson ${ }^{2,4} \cdot$ Anders Wåhlin $^{2,4} \cdot$ Katrine Riklund $^{2,4} \cdot$ Ulman Lindenberger ${ }^{5,7,8}$. \\ Martin Lövdén ${ }^{1} \cdot$ Lars Nyberg $^{2,3,4} \cdot$ Lars Bäckman $^{1}$
}

Received: 21 March 2019 / Accepted: 9 August 2019/ Published online: 23 August 2019

(c) The Author(s) 2019

\begin{abstract}
The dopamine D2/3 system is fundamental for sensory, motor, emotional, and cognitive aspects of behavior. Small-scale human histopathological and animal studies show high density of D2/3 dopamine receptors (D2/3DR) in striatum, but also demonstrate the existence of such receptors across cortical and limbic regions. Assessment of $\mathrm{D} 2 / 3 \mathrm{DR} \mathrm{BP}_{\mathrm{ND}}$ in the extrastriatal regions with $\left[{ }^{11} \mathrm{C}\right]$ raclopride has long been considered unreliable due to the relatively low density of D2/3DR outside the striatum. We describe the distribution and interregional links of D2/3DR availability measured with PET and $\left[{ }^{11} \mathrm{C}\right]$ raclopride across the human brain in a large sample $(N=176$; age range 64-68 years). Structural equation modeling revealed that D2/3DR availability can be organized according to anatomical (nigrostriatal, mesolimbic, mesocortical) and functional (limbic, associative, sensorimotor) dopamine pathways. D2/3DR availability in corticolimbic functional subdivisions showed differential associations to corresponding striatal subdivisions, extending animal and pharmacological work. Our findings provide evidence on the dimensionality and organization of $\left[{ }^{11} \mathrm{C}\right]$ raclopride D2/3DR availability in the living human brain that conforms to known dopaminergic pathways.
\end{abstract}

Keywords $\left[{ }^{11} \mathrm{C}\right]$ raclopride $\cdot$ Dopamine D2/3 receptors · Inter-individual differences $\cdot$ Structural-equation modeling . COBRA study

\section{Introduction}

Positron emission tomography (PET) can be used to quantify dopamine (DA) receptors in the human brain, using radioligands that bind selectively to the receptors of interest. $\left[{ }^{11} \mathrm{C}\right]$

Electronic supplementary material The online version of this article (https://doi.org/10.1007/s00429-019-01938-1) contains supplementary material, which is available to authorized users.

Goran Papenberg

goran.papenberg@ki.se

1 Aging Research Center, Karolinska Institutet and Stockholm University, Tomtebodavägen 18A, 17165 Solna, Sweden

2 Umeå Center for Functional Brain Imaging (UFBI), Umeå University, Umeå, Sweden

3 Department of Integrative Medical Biology, Umeå University, Umeå, Sweden

4 Department of Radiation Sciences, Umeå University, Umeå, Sweden raclopride is a well-validated tracer for assessment of striatal D2/3 DA receptor (D2/3DR) availability (or binding potential to non-displaceable tissue uptake; $\left.\mathrm{BP}_{\mathrm{ND}}\right)($ e.g., de Manzano et al. 2013; Egerton et al. 2010; Kim et al. 2014; Volkow et al. 2009). Competitive assay experiments in rhesus monkeys (Lidow et al. 1989) have documented that raclopride is a potent and selective D2/3DR ligand, which can be displaced from its binding sites only by D2/3DRselective drugs in striatal and extrastriatal regions alike.

5 Center for Lifespan Psychology, Max Planck Institute for Human Development, Berlin, Germany

6 Wallenberg Centre for Molecular Medicine, Umeå University, Umeå, Sweden

7 Max Planck, UCL Centre for Computational Psychiatry and Ageing Research, Berlin, Germany

8 Max Planck, UCL Centre for Computational Psychiatry and Ageing Research, London, UK 
Assessment of $\mathrm{D} 2 / 3 \mathrm{DR} \mathrm{BP}_{\mathrm{ND}}$ in extrastriatal regions with $\left[{ }^{11} \mathrm{C}\right]$ raclopride has long been considered unreliable due to the relatively low density of D2/3DR outside the striatum (Hall et al. 1994; Farde et al. 1988). However, a study reported acceptable reliability for $\mathrm{BP}_{\mathrm{ND}}$ based on $\left[{ }^{11} \mathrm{C}\right]$ raclopride in brain areas with low D2/3DR densities $(n=7$; Alakurtti et al. 2015). More specifically, intraclass correlation coefficients (ICCs) for cortical areas indicated moderate to good reproducibility (e.g., temporal cortex: 0.79 ; dorsolateral prefrontal cortex: 0.86; superior and inferior frontal gyrus: 0.64 and 0.67$)$. A more recent study reported similarly high ICCs across 7 months for $\left[{ }^{11} \mathrm{C}\right]$ raclopride $\mathrm{BP}_{\mathrm{ND}}$ in both striatal and extrastriatal brain regions $(n=27$; ICCs $>0.9$ for frontal and temporal cortex; Karalija et al. 2019). This suggests that extrastriatal $\left[{ }^{11} \mathrm{C}\right]$ raclopride $\mathrm{BP}_{\mathrm{ND}}$ values represent a true signal rather than mere noise. Here, we describe the "landscape" of $\left[{ }^{11} \mathrm{C}\right]$ raclopride $\mathrm{BP}_{\mathrm{ND}}$ in the human brain and investigate whether D2/3DR availability is organized according to anatomical and functional dopamine pathways, which would support the validity of extrastriatal $\left[{ }^{11} \mathrm{C}\right]$ raclopride measurements.

Dopaminergic projections, originating from the midbrain, densely innervate the striatum via the nigrostriatal pathway and, to a lesser degree, limbic and cortical areas via the mesolimbic and mesocortical pathways (Fig. 1a; Foote and Morrison 1987; Martinez et al. 2003; Haber and Knutson 2010; Cervenka et al. 2008). Striatum can also be functionally subdivided into limbic, associative, and sensorimotor parts based on corticostriatal projections (Foote and Morrison 1987; Haber and Knutson 2010; Tziortzi et al. 2014; Haber et al. 2006; Fig. 1b). The associative and sensorimotor pathways receive common dopaminergic innervation from the substantia nigra. The ventral tegmental area (VTA) provides dopaminergic input to the ventral striatum, as well as to limbic and neocortical areas via the mesolimbic and mesocortical pathways (Fig. 1a). With respect to the corticostriatal projections, the ventral striatum receives projections from the medial and orbitofrontal cortex, anterior cingulate cortex, as well as hippocampus and amygdala. The associative circuit involves dorsolateral prefrontal cortex, anterior cingulate cortex, and associative striatum (pre-commissural putamen and dorsal caudate nucleus). The anterior cingulate cortex is anatomically considered part of the limbic system, but is also connected to the associative cortices and projects to the associative striatum (Haber et al. 2006). Finally, the sensorimotor circuit encompasses the sensorimotor striatum (post-commissural part of dorsal putamen) and cortical areas, such as the precentral gyrus, postcentral gyrus, and superior parietal cortex.

We use structural equation modeling that accommodates the formation of latent factors that represent the common variance of their indicators. This method effectively separates out measurement error, and hence yields better estimates of factor variances and covariances (Little et al. 1999). We investigate between-person differences in D2/3DR availability across targeted brain regions belonging to anatomically defined pathways (i.e., striatal, limbic, neocortical). Given that corticostriatal projections impose a specific functional organization upon the striatum (Haber and McFarland 1999), we also examine whether individual differences in the $\left[{ }^{11} \mathrm{C}\right]$ raclopride $\mathrm{BP}_{\mathrm{ND}}$ data support a functional subdivision of cortical areas, such that target regions belonging to the same functional loop also load on the same latent factor. A good fit for these models would support the use of $\left[{ }^{11} \mathrm{C}\right]$

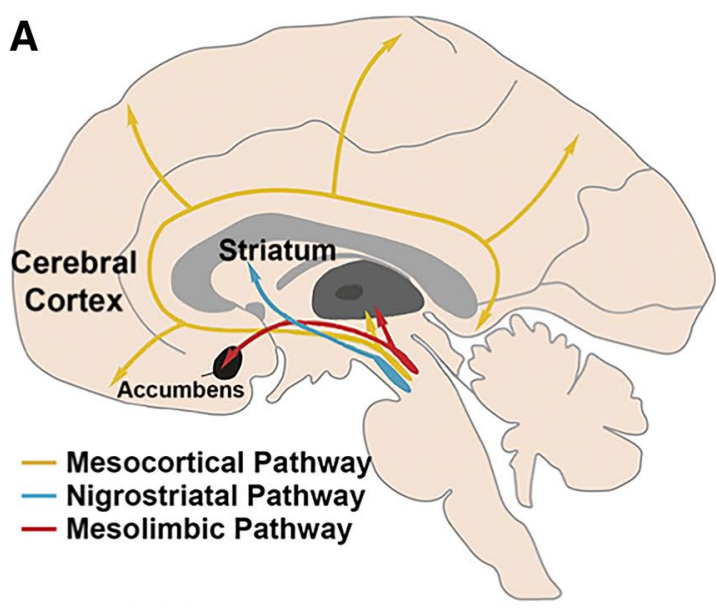

Fig. 1 a Schematic illustration of the major dopaminergic pathways in the brain. Adapted from $\mathrm{Li}$ et al. (2009), with permission from Oxford University Press. b Schematic illustration of corticostriatal projections and spiral striato-midbrain-striatal pathways. $M P F C$ medial prefrontal cortex, $O F C$ orbitofrontal cortex, $A C C$ anterior cin-

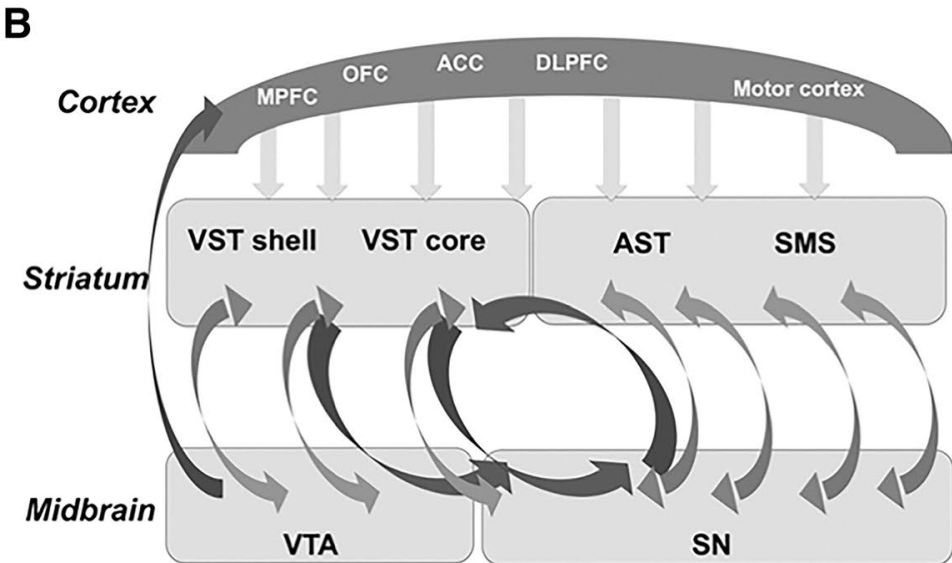

gulate cortex, $D L P F C$ dorsolateral prefrontal cortex, VST ventral striatum, $A S T$ associative striatum, SMS sensorimotor striatum, VTA ventral tegmental area, $S N$ substantia nigra. Reprinted from Rieckmann et al. (2011), with permission from Oxford University Press 
raclopride $\mathrm{BP}_{\mathrm{ND}}$ data to measure $\mathrm{D} 2 / 3 \mathrm{DR}$ availability along known dopaminergic pathways across the brain. Moreover, we study whether the resulting functional corticostriatal factors are specifically related to their corresponding striatal targets.

\section{Materials and methods}

The Cognition, Brain, and Aging (COBRA) study design, recruitment procedure, imaging protocols, and details of the cognitive and lifestyle battery have been reported elsewhere (Nevalainen et al. 2015). The study was approved by the local Ethical and Radiation Safety Committee of Umeå, Sweden, and all participants provided signed written informed consent prior to testing. Written consent was also acquired for storage of blood samples at Norrland's University Hospital.

\section{Participants}

The initial sample included 181 healthy older individuals (64-68 years of age; mean $=66.2 ; \mathrm{SD}=1.2 ; 81$ women $)$ who were randomly selected from the population register of Umeå, a city in northern Sweden. $\left[{ }^{11} \mathrm{C}\right]$ raclopride $\mathrm{BP}_{\mathrm{ND}}$ data were excluded for four individuals with imperfect segmentation of MR images and PET-MR image coregistration and for one individual with pathological deviations in the brain observed on the MR images. Thus, the effective sample included 176 individuals.

\section{PET image acquisition}

All participants underwent a PET scan (Discovery PET/CT 690; GE Healthcare) performed during resting-state conditions following an intravenous bolus injection of $250 \mathrm{MBq}$ $\left[{ }^{11} \mathrm{C}\right]$ raclopride. Preceding the injection, a 5-min low-dose helical CT scan $(20 \mathrm{~mA}, 120 \mathrm{kV}, 0.8 \mathrm{~s}$ per revolution) was obtained for the purpose of PET-attenuation correction. Following the bolus injection, a 55-min 18-frame dynamic scan was acquired. Attenuation- and decay-corrected PET images (47 slices, field of view $25 \mathrm{~cm}, 256 \times 256$-pixel transaxial images, voxel size $0.977 \times 0.977 \times 3.27 \mathrm{~mm}^{3}$ ) were reconstructed with the iterative VUE Point HD-SharpIR algorithm (GE Healthcare); 6 iterations, 24 subsets, $3.0 \mathrm{~mm}$ postfiltering, yielding full width at half maximum of $3.2 \mathrm{~mm}$ (Wallsten et al. 2013). For comparative purposes, reconstruction was also performed with filtered-back projection (FBP; filter size: $6.4 \mathrm{~mm}$ ). FBP is a reconstruction technique, which is often seen as a quantitative "gold standard" for larger regions. However, the image noise is rather high, which may cause FBP images to contain pixels with negative uptake values. Iterative techniques produce less noisy images, but converge at different rates for high and low uptakes. Thus, iterative techniques produce less noise, but at a possible cost of bias, especially at lower ranges (Walker et al. 2011; Jian et al. 2015; van Velden et al. 2009). Therefore, it is essential to validate extrastriatal findings with FBP reconstruction. Head movements during the imaging sessions were minimized with an individually fitted thermoplastic mask attached to the bed surface.

\section{PET data analyses}

D2/3DR availability was determined by calculating $\left[{ }^{11} \mathrm{C}\right]$ raclopride $\mathrm{BP}_{\mathrm{ND}}$ (Mintun et al. 1984; Innis et al. 2007; Logan et al. 1996). In brief, the PET emission scan format was converted from DICOM to NIfTI, corrected for head movements, and then coregistered to the corresponding MR image using the Statistical Parametric Mapping software (SPM8; Ashburner and Friston 2005). Regions of interest were delineated with the FreeSurfer 5.3 segmentation software (Han and Fischl 2007; Fischl et al. 2004; Fischl et al. 2002). Time-activity curves for striatal and extrastriatal regions and the cerebellum were used to calculate $\mathrm{BP}_{\mathrm{ND}}$ using the Logan et al. (1996) graphical analysis, using perpendicular linear regression to minimize bias (Varga and Szabo 2002). The cerebellar gray matter was used as a reference region due to negligible D2/3DR expression (Camps et al. 1989; Farde et al. 1986; Levey et al. 1993). Median $\mathrm{BP}_{\mathrm{ND}}$ data were extracted for all regions of interest based on the subcortical parcellations in FreeSurfer and the Desikan-Killiany atlas (Desikan et al. 2006) for extrastriatal regions. In addition, Brodmann areas 9 and 46 were defined based on masks from the MRIcron atlas (http://people.cas. sc.edu/rorden/mricron/index.html), as those are not available in the Desikan-Killiany atlas.

Notably, there are several possibilities in PET that could cause inflated extrastriatal BP or bias, all of which can be ruled out in our data set. First, bias could be introduced by iterative reconstruction methods, which is not present in FBP analysis. Toward this end, the correlations among brain regions are virtually identical in size when using FBP (see Table S1). A second possibility for a bias is noisy data in Logan analysis (Slifstein and Laruelle 2000). A method to remove such bias has been reported applying perpendicular linear regression (Varga and Szabo 2002), which was also done here before calculating BPs. Third, partial-volume effects due to the PET resolution may cause "spill-out" of radioactivity outside the high striatal uptake to nearby areas. The distance of this potential spill-out is related to the PET resolution, which for our scanner and iterative reconstruction algorithm was $3.2 \mathrm{~mm}$ radially and $4.7 \mathrm{~mm}$ axially full-width half maximum (Wallsten 
et al. 2013). This resolution may give appreciable spillover at distances of the order of the resolution and this effect falls off quickly with distance, so that at four times the resolution $(20 \mathrm{~mm})$, no measurable effect is expected. Therefore, partial-volume effects are highly unlikely to cause measurable spillover from striatum to most cortical areas. That said, we cannot rule out some spillover to a few cortical regions, which are close enough. For instance, the most posterior part of the OFC may show some influence from the most anterior ventral striatum, and binding in the amygdala could impact adjacent parts of the temporal cortex.

A fourth origin of incorrect BP estimation and inflated correlations between regions has to do with reconstruction of projection data. Such effects are short range and also less of an issue with iterative reconstructions than with FBP (Razifar et al. 2005).

\section{Functional segmentation of striatum}

To segment the striatum into its functional pathways (limbic, associative, sensorimotor), we followed the procedures described by Tziortzi et al. (2014), who performed tractography on a younger sample (aged 25-55 years). Instead of using the available masks from Tziortzi et al., we used the available segmentation results from one of our previous studies ( $n=58$; aged 64-78 years), where DTI data was acquired on the same scanner and the age range was more similar to the COBRA study (Jonasson et al. 2016). Therefore, we considered our seeds as being better suited for analyzing the functional subdivisions. Subjectspecific striatal seeds were derived from FreeSurfer 5.3 (concatenated caudate, putamen, and nucleus accumbens), and Andri Tziortzi (GlaxoSmithKline) provided the three cortical target masks (limbic, associative, sensorimotor; see Tziortzi et al. (2014), for definition of masks).In short, using the FMRIB's diffusion toolbox (http://www.fmrib .ox.ac.uk/fsl/), a model estimating crossing fibers within voxels was run on eddy current corrected and betted diffusion weighted volumes (Behrens et al. 2007). Fibers originating from the striatum were tracked until they terminated in either of the three cortical targets. On the subject level, each striatal voxel was assigned to the cortical target to which it had the most terminating fibers to produce a subject-specific functional segmentation. This segmentation was then transformed to standard space by applying a transform created by normalizing a T1-weighted scan to the $1 \mathrm{~mm}$ non-linear MNI template using FMRIB's nonlinear registration toolbox (FNIRT). In standard space, each striatal voxel was assigned to the functional target to which most subjects had their corresponding voxels assigned.

\section{Statistical analyses}

One-sample $t$ tests were conducted to determine whether D2/3DR availability were reliably greater than zero, particularly for extrastriatal regions. To facilitate comparability, we describe mean $\left[{ }^{11} \mathrm{C}\right]$ raclopride $\mathrm{BP}_{\mathrm{ND}}$ for the same regions of interest as used by Hall et al. (1994), who quantified D2/3DR availability in six post-mortem brains using $\left[{ }^{3} \mathrm{H}\right]$ raclopride. We directly compare their measure of receptor density (i.e., $B_{\max }$ ) with our data of $\mathrm{BP}_{\mathrm{ND}}$ at the group level, using Spearman's correlations. Values for $B_{\max }$ based on $\left[{ }^{3} \mathrm{H}\right]$ raclopride from Hall et al. (Fig. 1b in the original publication) were digitized with the PlotDigitizer software (http://plotdigiti zer.sourceforge.net) and are reported in the supplementary (Table S2). Moreover, we also compared regional $\left[{ }^{11} \mathrm{C}\right]$ raclopride $\mathrm{BP}_{\mathrm{ND}}$ values with values determined with the highaffinity ligand $\left[{ }^{18} \mathrm{~F}\right]$ fallypride (Seaman et al. 2019; https:// osf.io/h67k4/). $\left[{ }^{18} \mathrm{~F}\right]$ fallypride data were obtained from older adults with a similar age range as in the COBRA study (aged $60-67, n=17)$.

Further analyses were conducted within the structural equation modeling framework, using AMOS 7.0 (Arbuckle 2006). We estimated two hierarchical models. Whereas the anatomical model explored the factor structure among striatum, limbic system, and neocortex (Fig. 2), the second model postulated that the functional subdivision of the limbic system and neocortex was a good representation of the $\mathrm{BP}_{\mathrm{ND}}$ data (Fig. 3).

Structural-equation modeling combines confirmatory factor analysis and multiple regression or covariance analysis, accommodating the specification of a theory-based statistical model. The confirmatory factor model part enables defining latent factors based on measured variables. One of the advantages of structural-equation models (SEM) is that latent factors are considered free of error. All variance common to the observed variables will be represented in their latent factor and all remaining variance is estimated as error (i.e., residual) variance. The regression or covariance part enables examining relationships among latent factors. Both parts are specified in a single model and the entire model is fitted to the data simultaneously. That is, variances and covariances of all variables in the data are compared to the variances and covariances implied by the model. A number of well-established fit indices are used to evaluate how well the model fits the data. If a specific model does not represent the data well, then this will be reflected in unacceptable fit indices and should be rejected (for further information on the use of SEM in cognitive neuroscience, see Kievit et al. 2017).

Following standard notation (Boker et al. 2009), in Figs. 2 and 3 boxes indicate observed variables, circles represent latent factors, arrows denote factor loadings, and 


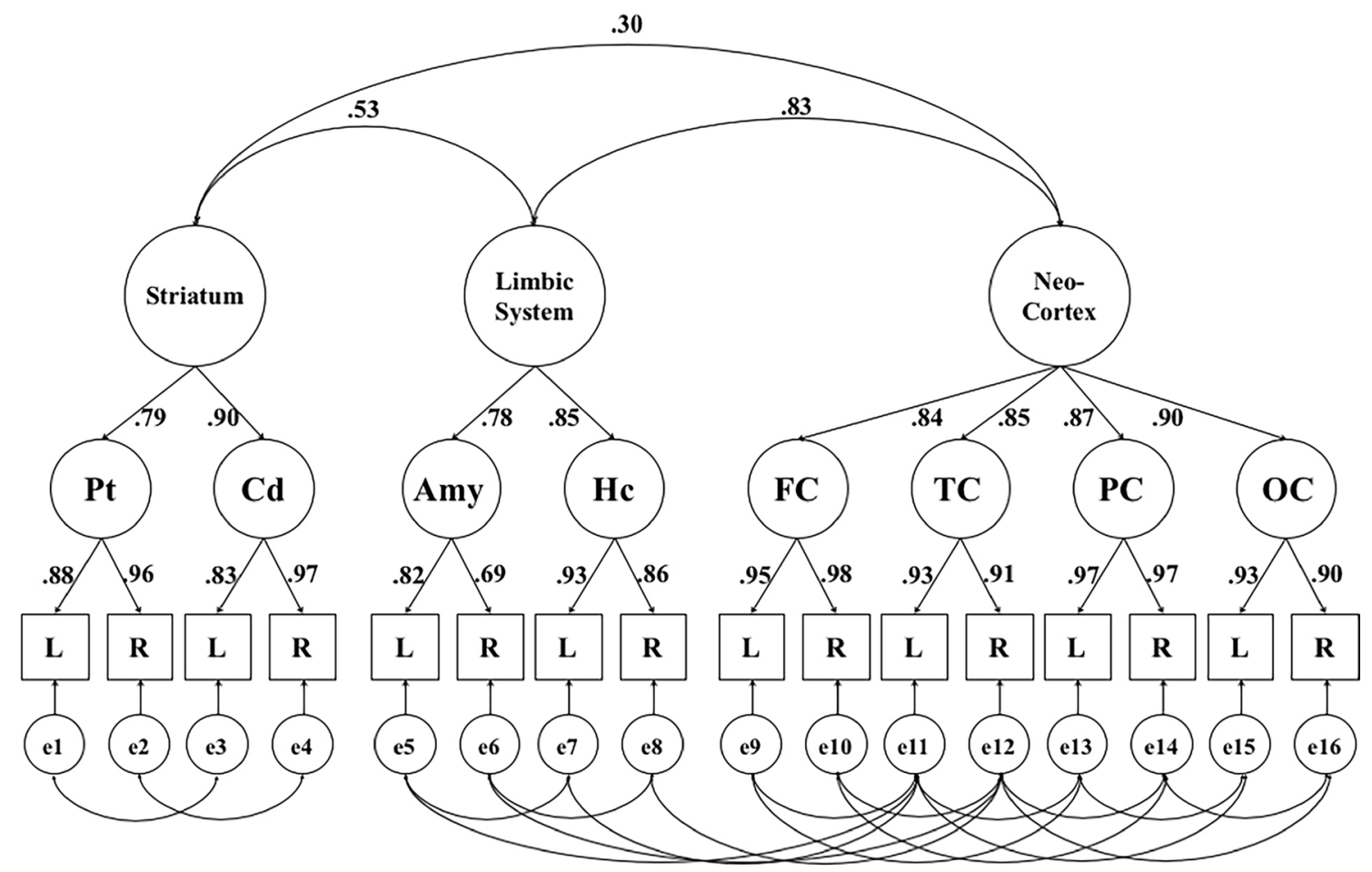

Fig. 2 Hierarchical factor model portraying the relationship between $\left[{ }^{11} \mathrm{C}\right]$ raclopride $\mathrm{D} 2 / 3 \mathrm{DR} \mathrm{BP}_{\mathrm{ND}}$ in striatum, limbic system, and neocortex. The figure shows standardized factor loadings and factor correlations for this model. Pt putamen, $C d$ caudate, $H c$ hippocampus, Amy amygdala, $F C$ frontal cortex, $O C$ occipital cortex, $T C$ temporal cortex, $P C$ parietal cortex, $L$ left hemisphere, $R$ right hemisphere, $e$ error. Errors represent hemisphere-specific variance and hemispherespecific measurement error. For any indicator, the variance accounted for by its error term corresponds to one minus the square of its factor loading

46), and sensorimotor (precentral gyrus, postcentral gyrus, superior parietal cortex) regions. Given that the anterior cingulate cortex (ACC) is associated with both the limbic and associative loops, as described above, its first-order latent factor loads on both the limbic and associative factor. Again, for comparative purposes, we fitted an alternative model positing that common variance across the indicators (Fig. 3) generalizes across the brain, so that all indicators load on one general factor (Figure S1).

In the next step, the latent factors of the corticolimbic subdivisions were related to the corresponding $\mathrm{BP}_{\mathrm{ND}}$ values for ventral, associative, and sensorimotor striatum. Whenever a particular striatal subdivision of interest was associated with multiple corticolimbic factors, we report associations adjusted for the other two subdivisions to determine the unique links. Residual variances, which are variances not explained by the latent factors, were allowed to covary between neighboring brain areas in all models (Figs. 2, 3). We evaluated whether the models provided a good representation of the data, using the root mean square error of approximation (RMSEA) and the comparative fit index [CFI; see Kline 2005, for interpretation of these indices)]. Values $\leq 0.08$ for RMSEA and $\geq 0.90$ for CFI were considered to indicate good model fit. 


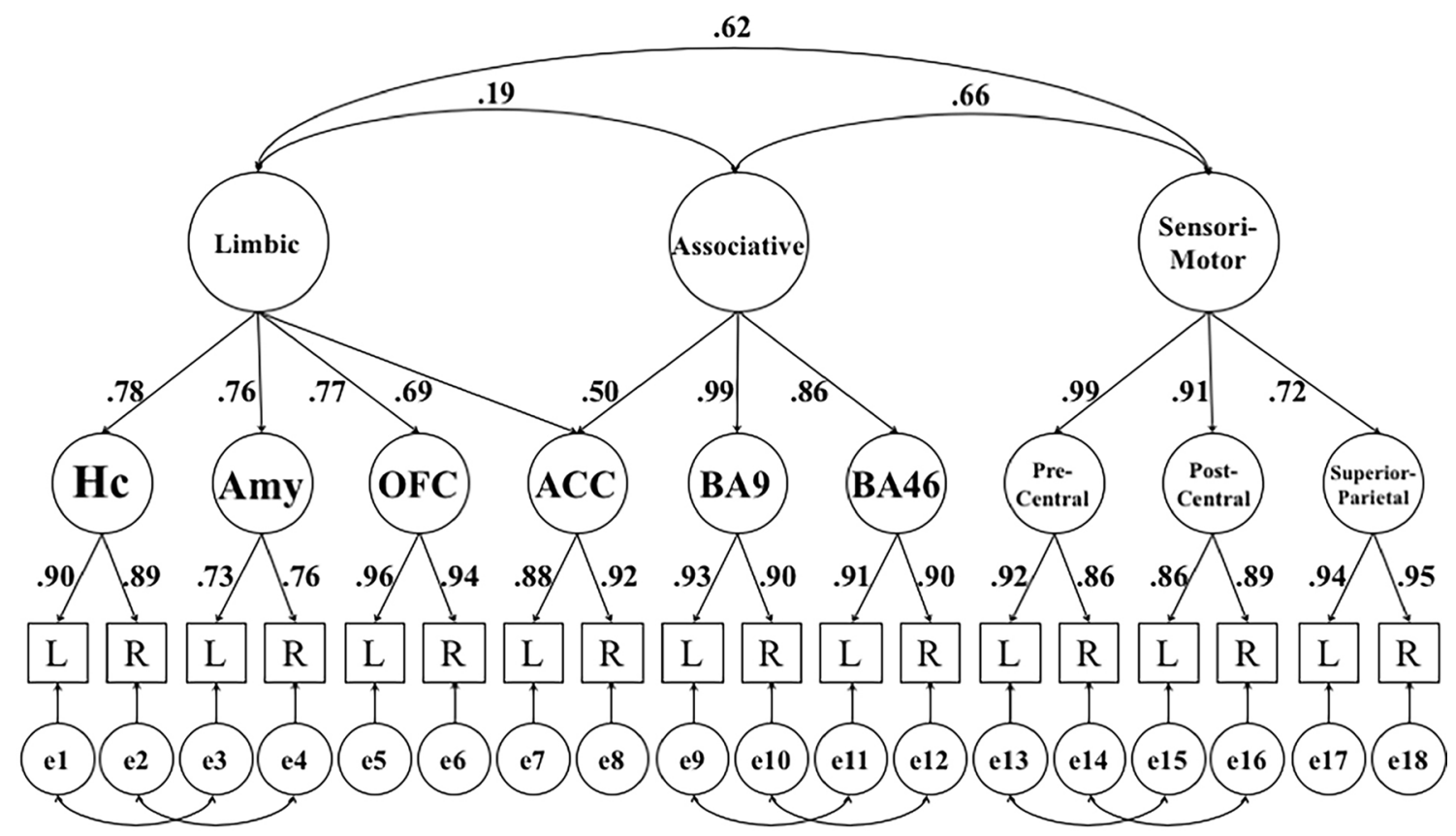

Fig. 3 Hierarchical factor model reflecting interrelations of $\left[{ }^{11} \mathrm{C}\right]$ raclopride $\mathrm{D} 2 / 3 \mathrm{DR} \mathrm{BP}_{\mathrm{ND}}$ between functional subdivisions in extrastriatal regions. The figure shows standardized factor loadings and factor correlations for this model. $H c$ hippocampus, Amy amygdala, $O F C$ orbito-frontal cortex (lateral, medial), $A C C$ anterior cingulate cortex, BA9 Brodmann Area 9, BA46 Brodmann Area 46, Precen-

Both univariate $( \pm 3.29 \mathrm{SD})$ and multivariate outliers (Mahalanobi's distance; $p<0.001$ threshold for the $\chi^{2}$ value) were excluded from analyses and treated as missing by the program $(<1 \%$ of values; Tabachnick and Fidell 2006). All variables displayed acceptable skewness and kurtosis (i.e., values not exceeding \pm 1.5 ). In all analyses, the alpha level for statistical decisions was set to 0.05 .

\section{Results}

\section{Landscape of D2/3DR availability in neocortical and subcortical areas}

Figure 4 depicts $\mathrm{D} 2 / 3 \mathrm{DR} \mathrm{BP}_{\mathrm{ND}}$ values for striatal and extrastriatal regions (see Table $\mathrm{S} 3$ for specific values). All values, except for the corpus callosum, were reliably different from zero $(p s<0.05)$. The corresponding numbers for data based on FBP reconstruction were highly similar (Figure S2). Importantly, D2/3DR $\mathrm{BP}_{\mathrm{ND}}$ correlates very highly with $B_{\max }$ reported by Hall et al. (Fig. 5b), supporting the validity of our data (Spearman's correlation: $r=0.841 ; p=0.000)$. The correlation was attenuated after excluding the striatum and globus pallidus (Spearman's correlation: $r=0.533, p=0.139$; Fig. $5 \mathrm{a}$ ). Note, however, that $B_{\max }$ values varied largely across frontal regions tral precentral gyrus, Postcentral postcentral gyrus, Superior parietal superior parietal lobule, $L$ left hemisphere, $R$ right hemisphere, $e$ error. Errors represent hemisphere-specific variance and hemispherespecific measurement error. For any indicator, the variance accounted for by its error term corresponds to one minus the square of its factor loading

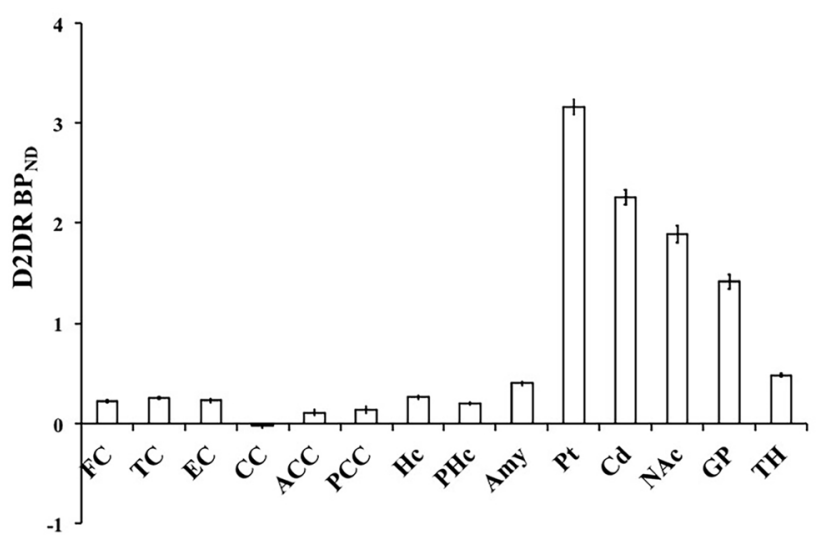

Fig. 4 Mean $\left[{ }^{11} \mathrm{C}\right]$ raclopride $\mathrm{D} 2 / 3 \mathrm{DR} \mathrm{BP}_{\mathrm{ND}}$ across brain regions. $F C$ frontal cortex (superior, medial, oribital), $T C$ temporal cortex (superior, middle), $E C$ entorhinal cortex, $C C$ corpus callosum, $A C C$ anterior cingulate cortex, $P C C$ posterior cingulate cortex, $H c$ hippocampus, $P H c$ parahippocampus, Amy amygdala, $P t$ putamen, $C d$ caudate, $N A c$ nucleus accumbens, $G P$ globus pallidus, $T H$ thalamus. Error bars represent $95 \%$ confidence intervals around the means

(Table $\mathrm{S} 2$ in supplementary). $B_{\max }$ of the superior frontal cortex was five times greater than $B_{\max }$ in the medial and three times greater than $B_{\max }$ in the orbitofrontal cortex, suggesting an overestimation of the superior frontal cortex. The very high $B_{\max }$ for the superior frontal cortex is 

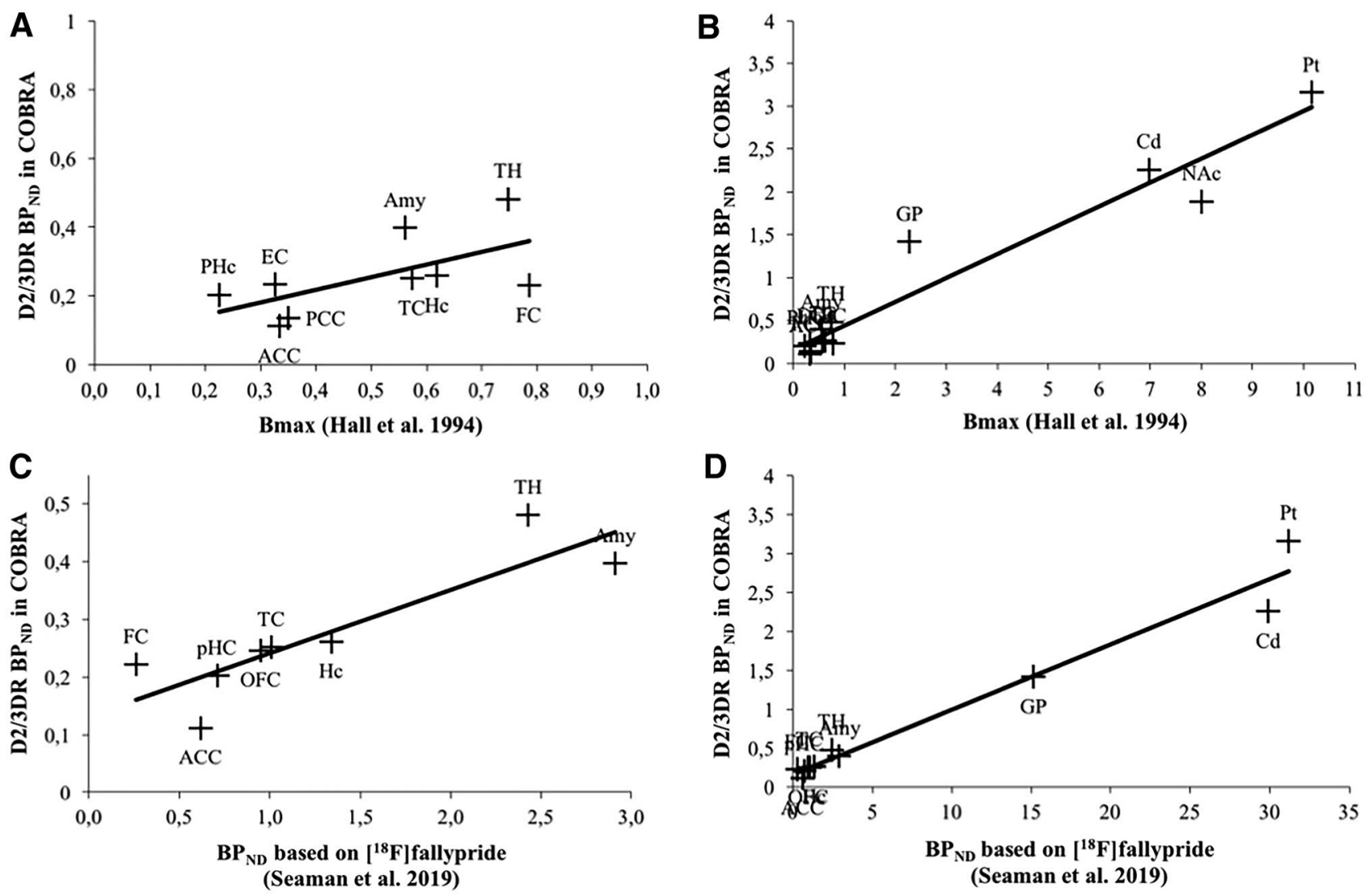

Fig. 5 Relationship between $\left[{ }^{11} \mathrm{C}\right]$ raclopride $\mathrm{D} 2 / 3 \mathrm{DR} \quad \mathrm{BP}_{\mathrm{ND}}$ in COBRA and receptor density $\left(B_{\max }\right)$ in post-mortem brains as reported by Hall et al. (1994) across extrastriatal regions of interest (a) and including the striatum and globus pallidus (b). Relationship between $\left[{ }^{11} \mathrm{C}\right]$ raclopride $\mathrm{D} 2 / 3 \mathrm{DR} \mathrm{BP}_{\mathrm{ND}}$ in COBRA and $\mathrm{BP}_{\mathrm{ND}}$ based on $\left[{ }^{18} \mathrm{~F}\right]$ fallypride (Seaman et al. 2019) across extrastriatal regions of interest (c) and including the striatum and globus pallidus (d). $F C$ frontal cortex (Hall superior, medial, orbital in $\mathbf{a}$ and $\mathbf{b}$, Seaman middle, superior, and inferior frontal gyrus, in $\mathbf{c}$ and $\mathbf{d}, C O B R A$ superior frontal gyrus, rostral middle-frontal gyrus, medial orbital frontal cor-

also inconsistent with $\left[{ }^{18} \mathrm{~F}\right]$ fallypride-PET data, which suggest similar levels of D2/3DRs across superior and medial frontal areas and relatively higher D2/3DR levels in orbital areas (Seaman et al., 2019). Excluding the superior frontal cortex revealed a strong correlation among regions with very low D2 density (Spearman's correlation: $r=0.767, p=0.016$ ). In line with the post-mortem data, $\mathrm{BP}_{\mathrm{ND}}$ based on $\left[{ }^{11} \mathrm{C}\right]$ raclopride correlated very highly with previously published $\left[{ }^{18} \mathrm{~F}\right]$ fallypride $\mathrm{BP}_{\mathrm{ND}}$ across extrastriatal regions (Spearman's correlation: $r=0.907 ; p=0.002$; Fig. 5c), which was similar to the association obtained when including regions with high D2 density (Spearman's correlation: $r=0.964 ; p=0.000$; Fig. $5 \mathrm{~d}$ ). Notably, the positive correlation between our $\mathrm{BP}_{\mathrm{ND}}$ estimates and both post-mortem and $\left[{ }^{18} \mathrm{~F}\right]$ fallypride data occur despite differences in ROI definition. Data from Seaman et al. are based

tex in $\mathbf{a}$ and $\mathbf{b}$ and superior frontal and rostral middle-frontal gyrus in $\mathbf{c}$ and $\mathbf{d}$ ), $T C$ temporal cortex (Hall superior and middle-temporal cortex in $\mathbf{a}$ and $\mathbf{b}$, Seaman superior, middle, and inferior temporal gyrus in $\mathbf{c}$ and $\mathbf{d}, C O B R A$ superior and middle-temporal gyrus); $E C$ entorhinal cortex, $C C$ corpus callosum, $A C C$ anterior cingulate cortex, $O F C$ orbitofrontal cortex (Seaman, anterior, medial, lateral, and posterior orbital gyrus, COBRA medial orbital frontal cortex), $P C C$ posterior cingulate cortex, $H c$ hippocampus, $P H c$ parahippocampus, Amy amygdala, $P t$ putamen, $C d$ caudate, $N A c$ nucleus accumbens, $G P$ globus pallidus, $T H$ thalamus

on the Hammers atlas, whereas our ROI data are based on the Desikan-Killiany atlas.

Finally, Figures S3 and S4 illustrate similarities in time-activity curves and kinetics for regions with high (striatum) and low receptor density (frontal cortex), as compared to the reference region.

\section{Model including striatal, limbic, and neocortical factors}

A model representing striatal, limbic, and neocortical second-order latent factors (Fig. 2) showed good fit, $\chi^{2}$ (75, $n=176)=147.2, p<0.05, \mathrm{CFI}=0.97$, RMSEA $=0.074$, $\mathrm{CI}_{\text {RMSEA }}(0.056,0.092)$. Correlations among indicators for this model are also shown in Table S4. Standardized factor loadings of the indicators for the first-order factors were high, reflecting high correlations between hemispheres. 
Table 1 Latent mean estimates of the hierarchical factor model portraying the relationship between $\left[{ }^{11} \mathrm{C}\right]$ raclopride $\mathrm{D} 2 / 3 \mathrm{DR} \mathrm{BP}_{\mathrm{ND}}$ in striatum, limbic system, and neocortex

\begin{tabular}{lll}
\hline ROI & Latent mean & SE \\
\hline Pt & 3.06 & 0.020 \\
Cd & 2.21 & 0.020 \\
Amy & 0.41 & 0.005 \\
Hc & 0.27 & 0.004 \\
FC & 0.19 & 0.003 \\
TC & 0.25 & 0.003 \\
PC & 0.20 & 0.003 \\
OC & 0.24 & 0.003 \\
\hline
\end{tabular}

$R O I$ region of interest, $P t$ putamen, $C d$ caudate, Amy amygdala, $H c$ hippocampus, $F C$ frontal cortex, $T C$ temporal cortex, $P C$ parietal cortex, $O C$ occipital cortex, $S E$ standard error

All latent means are significantly different from zero at $p<0.001$

Similarly, the first-order factors loaded highly on the second-order factors, indicating high correlations among hierarchically organized striatal, limbic, and neocortical regions. Finally, striatal D2/3DR $\mathrm{BP}_{\mathrm{ND}}$ was positively correlated with neocortex $(r=0.30)$ and the limbic system $(r=0.53)$, although these two correlations could not be constrained to be equal without loss in fit $\left(\Delta \chi^{2}(1, n=176)=18.6\right.$, $p<0.05)$. The inter-factor correlation between D2/3DR $\mathrm{BP}_{\mathrm{ND}}$ in limbic system and neocortex $(r=0.83)$ was only significantly higher than the striatum-neocortex association $\left(\Delta \chi^{2}(1, n=176)=12.2, p<0.05\right)$. Constraining this correlation to 1 resulted in a significantly worse fit, $\Delta \chi^{2}(1$, $n=176)=11.2, p<0.05$. This suggests that, despite the high correlation between the limbic system and neocortex, these two factors are separable. To test whether between-person differences generalize across the indicators, we also fitted a model in which all indicators load on one general factor. This model exhibited poor fit, $\chi^{2}(86, n=176)=1012.8$, $p<0.05, \mathrm{CFI}=0.64, \mathrm{RMSEA}=0.248, \mathrm{CI}_{\mathrm{RMSEA}}(0.235$, 0.262 ), suggesting that it represents the data inadequately (Table S5 for factor loadings). Latent means for first-order factors of the model shown in Fig. 2 are presented in Table 1.

\section{Functional subdivision of limbic and neocortical regions}

A model postulating a functional subdivision of limbic and neocortical regions (Fig. 3) showed good fit, $\chi^{2}(116$, $n=176)=236.2, p<0.05, \mathrm{CFI}=0.96$, RMSEA $=0.077$, $\mathrm{CI}_{\text {RMSEA }}$ (0.063, 0.091; see Table S6 for interrelationships among regions). Again, factor loadings for the first-order factors were high, reflecting high correlations between hemispheres. With respect to second-order factor loadings, ACC had equally high loadings on the limbic and associative factors, which is in line with its structural and functional
Table 2 Latent mean estimates of the hierarchical factor model reflecting interrelations of $\left[{ }^{11} \mathrm{C}\right]$ raclopride $\mathrm{D} 2 / 3 \mathrm{DR} \mathrm{BP}_{\mathrm{ND}}$ between functional subdivisions in extrastriatal regions

\begin{tabular}{lll}
\hline ROI & Latent mean & SE \\
\hline Hc & 0.27 & 0.004 \\
Amy & 0.41 & 0.005 \\
OFC & 0.24 & 0.003 \\
ACC & 0.24 & 0.004 \\
BA9 & 0.09 & 0.003 \\
BA46 & 0.17 & 0.003 \\
Precentral & 0.15 & 0.003 \\
Postcentral & 0.11 & 0.003 \\
Superior parietal & 0.16 & 0.004 \\
\hline
\end{tabular}

$R O I$ region of interest, $H c$ hippocampus, $A m y$ amygdala, $O F C$ orbitofrontal cortex (lateral, medial), $A C C$ anterior cingulate cortex, $B A 9$ Brodmann Area 9, BA46 Brodmann Area 46, Precentral precentral gyrus, Postcentral postcentral gyrus, Superior parietal superior parietal lobule, $S E$ standard error

All latent means are significantly different from zero at $p<0.001$

associations in the brain (Haber et al. 2006). All other limbic, associative, and sensorimotor first-order factors loaded well on their respective second-order factors. Interestingly, the sensorimotor factor correlated similarly strongly with both the limbic $(r=0.62 ; p<0.05)$ and associative $(r=0.66$; $p<0.05)$ factors, whereas the relationship between the limbic and associative factors was significantly weaker $(r=0.19 ; p<0.05)$, as indicated by a significant loss in fit after equating correlations ( $p s<0.05$ for $\Delta \chi^{2}$ ). An alternative model positing that $\mathrm{D} 2 / 3 \mathrm{DR}$ availability generalizes across functional DA pathways showed unacceptable fit, $\chi^{2}(129$, $n=176)=1247.3, p<0.05, \mathrm{CFI}=0.61$, RMSEA $=0.223$, $\mathrm{CI}_{\text {RMSEA }}(0.211,0.234)$, again suggesting that such a model represents the data inadequately (see Table $\mathrm{S} 7$ for factor loadings). Latent means for first-order factors of the model shown in Fig. 3 are presented in Table 2.

Next, we correlated the latent factors (Fig. 3) with the functional segmentation of the striatum (ventral, associative, sensorimotor; mean of left and right). In line with the hypothesized functional subdivisions, $\mathrm{BP}_{\mathrm{ND}}$ in the ventral striatum was positively related to $\mathrm{BP}_{\mathrm{ND}}$ for the cortical limbic factor $(r=0.27 ; p<0.05)$, whereas the relations to the associative $(r=-0.02$; n.s.) and sensorimotor $(r=-0.05$; n.s.) factors were not significant. Likewise, the associative striatum correlated positively with the associative factor $(r=0.30 ; p<0.05)$, after adjusting for the limbic and sensorimotor striatum. The correlations with the limbic $(r=-0.14$; n.s. $)$ and sensorimotor $(r=0.01$; n.s.) factors were not reliable. Significant and non-significant correlations were reliably different from each other $(p<0.05$ for Chi square difference tests, after equating correlations pairwise). Finally, the sensorimotor striatum correlated positively with 
the sensorimotor factor $(r=0.28 ; p<0.05)$, after adjusting for the ventral and associative striatum. In this case, a positive, albeit weaker, correlation was also observed with the limbic factor $(r=0.21 ; p<0.05)$, whereas the association with the associative factor was not significant $(r=0.10$; n.s.). Notably, the association with the sensorimotor factor was not reliably different from that with the limbic factor, but differed from the link to the associative factor $(p<0.05$ for Chi square difference tests). All critical correlations survived Bonferroni correction for nine comparisons $(p=0.006)$.

\section{Discussion}

We investigated the distribution and interregional associations of $\left[{ }^{11} \mathrm{C}\right]$ raclopride $\mathrm{BP}_{\mathrm{ND}}$ across the brain in a sample of 176 older adults. Between-person differences in D2/3DR availability measured with $\left[{ }^{11} \mathrm{C}\right]$ raclopride could be accounted for by an anatomical model (striatum, limbic system, and neocortex) as shown previously with the highaffinity ligand $\left[{ }^{18} \mathrm{~F}\right]$ fallypride (Zald et al. 2010). Importantly, we extended that study by showing that the data are organized according to known dopaminergic pathways across the striatum and cortex (limbic, associative, and sensorimotor), and by showing specific associations between the corresponding striatal and cortical functional divisions.

The use of $\left[{ }^{11} \mathrm{C}\right]$ raclopride to measure extrastriatal D2/3DR availability has long been considered unreliable due to the low density of D2/3DR (Farde et al. 1986). However, recent studies provided evidence of good test-retest reliability for raclopride in extrastriatal regions (Alakurtti et al. 2015; Karalija et al. 2019). There are several indications why $\left[{ }^{11} \mathrm{C}\right]$ raclopride is suitable for measuring the distribution of D2/3DR across the brain. First, we show that $\left[{ }^{11} \mathrm{C}\right]$ raclopride $\mathrm{BP}_{\mathrm{ND}}$ in extrastriatal regions is correlated with post-mortem (Hall et al. 1994) and $\left[{ }^{18} \mathrm{~F}\right]$ fallypride estimates of D2/3DR receptor density. Second, the SEM analyses further support both reliability and validity of $\left[{ }^{11} \mathrm{C}\right]$ raclopride in measuring extrastriatal $\mathrm{D} 2 / 3 \mathrm{DR} \mathrm{BP}_{\mathrm{ND}}$. The good model fit indicates both convergent and discriminant validity, as the organization of $\left[{ }^{11} \mathrm{C}\right]$ raclopride $\mathrm{BP}_{\mathrm{ND}}$ is in line with anatomical and functional DA pathways. Convergent validity is supported by the higher associations among regions that should, according to theory, correlate with each other (i.e., the strongest correlations were found between hemispheres and within DA pathways). At the same time, discriminant validity is supported by relatively weaker associations among regions that, according to theory, should be less strongly correlated. Further, the fact that the left and right hemisphere show such strong correlations, resulting in very high first-order factor loadings (around 0.9) suggests that there is a lot of shared variance, supporting the reliability of the measurements. Thus, overall, our findings demonstrate that extrastriatal
D2/3DR estimation with $\left[{ }^{11} \mathrm{C}\right]$ raclopride is associated with measures and patterns that result from target binding, rather than represent noise.

Our SEM analyses demonstrate good fit for a model assuming separate factors for striatal, limbic, and neocortical $\mathrm{BP}_{\mathrm{ND}}$, which are positively correlated. The link between the limbic system and neocortex was particularly high, which may be due to both being innervated by the VTA via the mesocortical and mesolimbic pathways (Fig. 1a). Importantly, our data are in line with a study using the high-affinity ligand $\left[{ }^{18} \mathrm{~F}\right]$ fallypride (Zald et al. 2010) to investigate interindividual differences in D2/3DR availability: Individual differences in D2-like $\mathrm{BP}_{\mathrm{ND}}$ were accounted for by three distinguishable factors, representing striatal, neocortical, and limbic regions. Moreover, only $10 \%$ of the variance in the overall cortical $\mathrm{D} 2$-like $\mathrm{BP}_{\mathrm{ND}}$ was accounted for by striatal D2-like $\mathrm{BP}_{\mathrm{ND}}$, which is almost identical to the current pattern of data ( $9 \%$ of explained variance). Thus, our conclusions regarding the anatomical factor structure based on extrastriatal $\left[{ }^{11} \mathrm{C}\right]$ raclopride data are highly similar to those derived from $\left[{ }^{18} \mathrm{~F}\right]$ fallypride data. Whereas our study is well powered and supports the reliability and validity of extrastriatal D2/3DR assessments with $\left[{ }^{11} \mathrm{C}\right]$ raclopride, high-affinity ligands such as $\left[{ }^{11} \mathrm{C}\right]-\mathrm{FLB} 457$ (Halldin et al. 1995) and $\left[{ }^{18} \mathrm{~F}\right]$ fallypride (Mukherjee et al. 2004) may still be more beneficial for extrastriatal D2/3DR assessments in studies with small sample sizes due to higher signal-to-noise ratios.

Furthermore, the structure of individual differences suggests that neocortical and limbic $\mathrm{BP}_{\mathrm{ND}}$ data are organized in accordance with functional subdivisions of the DA system (limbic, associative, sensorimotor). The association between the limbic and associative factors was reliably lower than that between the associative and sensorimotor factors. This likely reflects common dopaminergic innervation from the substantia nigra for the latter two cortical subdivisions (Martinez et al. 2003; Rieckmann et al. 2011). By contrast, mesolimbic and mesocortical areas both receive input from the VTA (Fig. 1). The functional subdivision pertaining to the corticolimbic $\mathrm{BP}_{\mathrm{ND}}$ data is further supported by the specificity of correlations for the limbic and associative factors with the corresponding striatal subdivisions. For the sensorimotor striatum, positive associations were observed with both sensorimotor and limbic regions. The latent correlations between the limbic and sensorimotor factors were high as well. Toward this end, a PET imaging study showed that administration of amphetamine induces larger reduction in D2/3DR availability in the ventral and sensorimotor striatum compared to associative regions (Martinez et al. 2003). As noted by Trifilieff and Martinez (2014), the sensorimotor striatum shares histochemical features with the ventral striatum (Fudge and Haber 2002) and receives glutamatergic input from amygdala and other limbic regions (Fudge and Haber 
2002; Fudge et al. 2004). This suggests that the sensorimotor striatum may also involve a limbic component, as reflected by the observed associations between D2/3DR $\mathrm{BP}_{\mathrm{ND}}$ in the sensorimotor striatum and corticolimbic areas.

DA-PET studies are typically characterized by relatively small sample sizes, which preclude examining interregional correlations of $\mathrm{BP}_{\mathrm{ND}}$ values in latent space. The observed interindividual differences in anatomical and functional DA pathways in the current sample likely originate from genetic influences that are further augmented by recursive relations between epigenetic and environmental factors that operate across the lifespan (Beam and Turkheimer 2013). Research shows that different interventions, such as cognitive training and physical exercise, can have selective effects on different parts of the DA system. For example, exercise training across 8 weeks in methamphetamine users increased their D2/3DR binding in striatum, with no effects in extrastriatal regions (Robertson et al. 2015). An intervention study targeting D2/3DR demonstrated increased striatal DA release following 5 weeks of working-memory training (Bäckman et al. 2011). Furthermore, candidate gene studies have reported that variations in the same single-nucleotide polymorphism, located in the $\mathrm{D} 2$ gene, influence $\mathrm{D} 2 / 3 \mathrm{DR} \mathrm{BP}_{\mathrm{ND}}$ differently in striatal (Hirvonen et al. 2009a) and extrastriatal (Hirvonen et al. 2009b) brain areas. These genetic effects may become magnified in aging (Papenberg et al. 2015), contributing to between-person differences in D2/3DR availability across the brain. Finally, the SEM approach enables studying D2/3DR distributions within and between anatomical and functional DA pathways. The novel models proposed may prove useful when investigating selective decline within and across pathways associated with the discussed genetic and lifestyle factors, but also in healthy aging (Bäckman et al. 2006) and neurological disorders (Heckman et al. 2016).

Collectively, our findings provide evidence on the dimensionality and organization of D2/3DR availability in the living human brain and support the reliability and validity of whole-brain measurements of D2/3DR availability with $\left[{ }^{11} \mathrm{C}\right]$ raclopride.

Acknowledgements Open access funding provided by Karolinska Institute. The work was funded by specific grants from the Swedish Research Council (grant numbers: 421-2012-648; 2012-2016 and 2017-02217; 2017-2020). This work was further funded by the Swedish Research Council, Umeå University, Umeå University-Karolinska Institute Strategic Neuroscience Program, the Knut and Alice Wallenberg Foundation, the Torsten and Ragnar Söderberg Foundation, an Alexander von Humboldt Research award, a donation of the Jochnick Foundation, Swedish Brain Power, Swedish Brain Foundation, Västerbotten County Council, Innovation Fund of the Max Planck Society, and a 2010 Leibniz Research Award from the German Research Foundation (DFG). The FreeSurfer analyses were performed on resources provided by the Swedish National Infrastructure for Computing (SNIC) at HPC2N in Umeå.
Author contributions LN, KR, ML, UL, and LB designed the research; NK performed research; GP, LJ, NK, MA, AS, YK, AW, JJ, and JA analyzed the data. GP, LJ, and LB wrote the manuscript, which was edited by all authors.

Data availability The data sets generated and analyzed during the current study are available from the corresponding author on reasonable request.

\section{Compliance with ethical standards}

Conflict of interest The authors state that they have no conflicts of interest regarding the manuscript.

Ethical approval All procedures performed in studies involving human participants were in accordance with the ethical standards of the institutional and/or national research committee and with the 1964 Helsinki Declaration and its later amendments or comparable ethical standards.

Informed consent Informed consent was obtained from all individual participants included in the study.

Open Access This article is distributed under the terms of the Creative Commons Attribution 4.0 International License (http://creativeco mmons.org/licenses/by/4.0/), which permits unrestricted use, distribution, and reproduction in any medium, provided you give appropriate credit to the original author(s) and the source, provide a link to the Creative Commons license, and indicate if changes were made.

\section{References}

Alakurtti K, Johansson JJ, Joutsa J, Laine M, Bäckman L, Nyberg L, Rinne JO (2015) Long-term test-retest reliability of striatal and extrastriatal dopamine D2/3 receptor binding: study with $\left[{ }^{11} \mathrm{C}\right]$ raclopride and high-resolution PET. J Cereb Blood Flow Metab 35(7):1199-1205. https://doi.org/10.1038/jcbfm.2015.53

Arbuckle JL (2006) Amos (Version 7.0) [Computer Program]. SPSS, Chicago

Ashburner J, Friston KJ (2005) Unified Segmentation. NeuroImage 26(3):839-851. https://doi.org/10.1016/j.neuroimage.2005.02.018

Bäckman L, Nyberg L, Lindenberger U, Li S-C, Farde L (2006) The correlative triad among aging, dopamine, and cognition: current status and future prospects. Neurosci Biobehav Rev 30(6):791807. https://doi.org/10.1016/j.neubiorev.2006.06.005

Bäckman L, Nyberg L, Soveri A, Johansson J, Andersson M, Dahlin E, Neely AS, Virta J, Laine M, Rinne JO (2011) Effects of working-memory training on striatal dopamine release. Science (New York, NY) 333(6043):718. https://doi.org/10.1126/science.12049 78

Beam CR, Turkheimer E (2013) Phenotype-environment correlations in longitudinal twin models. Dev Psychopathol 25:7-16. https:// doi.org/10.1017/S0954579412000867

Behrens TEJ, Johansen Berg H, Jbabdi S, Rushworth M, Woolrich MW (2007) Probabilistic diffusion tractography with multiple fibre orientations: what can we gain? NeuroImage 34(1):144-155. https:// doi.org/10.1016/j.neuroimage.2006.09.018

Boker SM, McArdle JJ, Neale M (2009) An algorithm for the hierarchical organization of path diagrams and calculation of components of expected covariance. Struct Equ Model 9(2):174-194. https:// doi.org/10.1207/S15328007SEM0902_2 
Camps M, Cortés R, Gueye B, Probst A, Palacios JM (1989) Dopamine receptors in human brain: autoradiographic distribution of D2 sites. Neuroscience 28(2):275-290

Cervenka S, Bäckman L, Cselényi Z, Halldin C, Farde L (2008) Associations between dopamine D2-receptor binding and cognitive performance indicate functional compartmentalization of the human striatum. NeuroImage 40(3):1287-1295. https://doi. org/10.1016/j.neuroimage.2007.12.063

Desikan RS, Segonne F, Fischl B, Quinn BT, Dickerson BC, Blacker D, Buckner RL et al (2006) An automated labeling system for subdividing the human cerebral cortex on MRI scans into gyral based regions of interest. NeuroImage 31(3):968-980. https:// doi.org/10.1016/j.neuroimage.2006.01.021

Egerton A, Shotbolt JP, Stokes PRA, Hirani E, Ahmad R, Lappin JM, Reeves SZ, Mehta MA, Howes OD, Grasby PM (2010) Acute effect of the anti-addiction drug bupropion on extracellular dopamine concentrations in the human striatum: an $\left[{ }^{11} \mathrm{C}\right]$ raclopride PET study. NeuroImage 50(1):260-266. https://doi. org/10.1016/j.neuroimage.2009.11.077

Farde L, Hall H, Ehrin E, Sedvall G (1986) Quantitative analysis of $\mathrm{D} 2$ dopamine receptor binding in the living human brain by PET. Science (New York, NY) 231(4735):258-261

Farde L, Pauli S, Hall H, Eriksson L, Halldin C, Högberg T, Nilsson L, Sjögren I, Stone-Elander S (1988) Stereoselective binding of ${ }^{11} \mathrm{C}$-raclopride in living human brain — a search for extrastriatal central D2-dopamine receptors by PET. Psychopharmacology 94(4):471-478. https://doi.org/10.1007/BF00212840

Fischl B, Salat DH, Busa E, Albert M, Dieterich M, Haselgrove C, van der Kouwe A et al (2002) Whole brain segmentation: automated labeling of neuroanatomical structures in the human brain. Neuron 33(3):341-355

Fischl B, Salat DH, van der Kouwe A, Makris N, Segonne F, Quinn BT, Dale AM (2004) Sequence-independent segmentation of magnetic resonance images. NeuroImage 23(Suppl 1):S69-S84. https://doi.org/10.1016/j.neuroimage.2004.07.016

Foote SL, Morrison JH (1987) Extrathalamic modulation of cortical function. Annu Rev Neurosci 10:67-95. https://doi.org/10.1146/ annurev.ne.10.030187.000435

Fudge JL, Haber SN (2002) Defining the caudal ventral striatum in primates: cellular and histochemical features. J Neurosci 22(23):10078-10082

Fudge JL, Breitbart MA, McClain C (2004) Amygdaloid inputs define a caudal component of the ventral striatum in primates. J Comp Neurol 476(4):330-347. https://doi.org/10.1002/ cne. 20228

Haber SN, Knutson B (2010) The reward circuit: linking primate anatomy and human imaging. Neuropsychopharmacology 35(1):4-26. https://doi.org/10.1038/npp.2009.129

Haber SN, McFarland NR (1999) The concept of the ventral striatum in nonhuman primates. Ann N Y Acad Sci 877:33-48

Haber SN, Kim K, Mailly P, Calzavara R (2006) Reward-related cortical inputs define a large striatal region in primates that interface with associative cortical connections, providing a substrate for incentive-based learning. J Neurosci 26(32):8368-8376. https:// doi.org/10.1523/JNEUROSCI.0271-06.2006

Hall H, Sedvall G, Magnusson O, Kopp J, Halldin C, Farde L (1994) Distribution of D1- and D2-dopamine receptors, and dopamine and its metabolites in the human brain. Neuropsychopharmacology 11(4):245-256. https://doi.org/10.1038/sj.npp.1380111

Halldin C, Farde L, Högberg T, Mohell N, Hall H, Suhara T, Karlsson P, Nakashima Y, Swahn CG (1995) Carbon-11-FLB 457: a radioligand for extrastriatal D2 dopamine receptors. J Nucl Med 36(7):1275-1281

Han X, Fischl B (2007) Atlas renormalization for improved brain MR image segmentation across scanner platforms. IEEE Trans Med Imaging 26(4):479-486. https://doi.org/10.1109/tmi.2007.893282
Heckman PRA, van Duinen MA, Bollen EPP, Nishi A, Wennogle LP, Blokland A, Prickaerts J (2016) Phosphodiesterase inhibition and regulation of dopaminergic frontal and striatal functioning: clinical implications. Int J Neuropsychopharmacol. https://doi. org/10.1093/ijnp/pyw030

Hirvonen MM, Laakso A, Någren K, Rinne JO, Pohjalainen T, Hietala J (2009a) C957T polymorphism of dopamine D2 receptor gene affects striatal DRD2 in vivo availability by changing the receptor affinity. Synapse 63(10):907-912. https://doi.org/10.1002/ syn. 20672

Hirvonen MM, Lumme V, Hirvonen J, Pesonen U, Nagren K, Vahlberg T, Scheinin H, Hietala J (2009b) C957T polymorphism of the human dopamine D2 receptor gene predicts extrastriatal dopamine receptor availability in vivo. Prog Neuro-Psychopharmacol Biol Psychiatry 33(4):630-636. https://doi.org/10.1016/j.pnpbp .2009 .02 .021

Innis RB, Cunningham VJ, Delforge J, Fujita M, Gjedde A, Gunn RN, Holden $\mathrm{J}$ et al (2007) Consensus nomenclature for in vivo imaging of reversibly binding radioligands. J Cereb Blood Flow Metab 27(9):1533-1539. https://doi.org/10.1038/sj.jcbfm.9600493

Jian Y, Planeta B, Carson RE (2015) Evaluation of bias and variance in low-count OSEM list mode reconstruction. Phys Med Biol 60(1):15-29. https://doi.org/10.1088/0031-9155/60/1/15

Jonasson LS, Nyberg L, Kramer AF, Lundquist A, Riklund K, Boraxbekk CJ (2016) Aerobic exercise intervention, cognitive performance, and brain structure: results from the physical influences on brain in aging (PHIBRA) study. Front Aging Neurosci 8:336. https://doi.org/10.3389/fnagi.2016.00336

Kim JH, Son Y-D, Kim H-K, Lee S-Y, Kim Y-B, Cho Z (2014) Dopamine $\mathrm{D}(2 / 3)$ receptor availability and human cognitive impulsivity: a high-resolution positron emission tomography imaging study with [(11)C]raclopride. Acta Neuropsychiatr 26(1):35-42. https://doi.org/10.1017/neu.2013.29

Karalija N, Jonasson L, Johannson J, Papenberg G, Salami A, Andersson M, Riklund K, Nyberg L, Boraxbekk CJ (2019) High 7-month test-retest reliability for extrastriatal ${ }^{11} \mathrm{C}$-raclopride binding in healthy older adults. J Cereb Blood Flow Metab (in press)

Kievit RA, Brandmaier AM, Ziegler G, van Harmelen AL, de Mooij SMM, Moutoussis M, Goodyer IM et al (2017) Developmental cognitive neuroscience using latent change score models: a tutorial and applications. Dev Cogn Neurosci. https://doi. org/10.1016/j.den.2017.11.007

Kline RB (2005) Principles and practice of structural equation modeling, 2nd edn. Guilford Press, New York

Levey AI, Hersch SM, Rye DB, Sunahara RK, Niznik HB, Kitt CA, Price DL, Maggio R, Brann MR, Ciliax BJ (1993) Localization of D1 and D2 dopamine receptors in brain with subtype-specific antibodies. Proc Natl Acad Sci USA 90(19):8861-8865

Li SC, Lindenberger U, Nyberg L, Heekeren HR, Bäckman L (2009) Dopaminergic modulation of cognition in human aging. In: Jagust W, D'Esposito M (eds) Imaging the aging brain. Oxford University Press, New York, pp 71-91

Lidow MS, Goldman-Rakic PS, Rakic P, Innis RB (1989) Dopamine D2 receptors in the cerebral cortex: distribution and pharmacological characterization with $\left[{ }^{3} \mathrm{H}\right]$ raclopride. Proc Natl Acad Sci USA 86(16):6412-6416

Little TD, Lindenberger U, Nesselroade JR (1999) On selecting indicators for multivariate measurement and modeling with latent variables: when 'good' indicators are bad and 'bad' indicators are good. Psychol Methods 4(2):192-211. https://doi. org/10.1037/1082-989x.4.2.192

Logan J, Fowler JS, Volkow ND, Wang GJ, Ding YS, Alexoff DL (1996) Distribution volume ratios without blood sampling from graphical analysis of PET data. J Cereb Blood Flow Metab 16(5):834-840. https://doi.org/10.1097/00004647-19960 9000-00008 
Manzano O, Cervenka S, Jucaite A, Hellenas O, Farde L, Ullen F (2013) Individual differences in the proneness to have flow experiences are linked to dopamine D2-receptor availability in the dorsal striatum. NeuroImage 67:1-6. https://doi.org/10.1016/j.neuro image.2012.10.072

Martinez D, Slifstein M, Broft A, Mawlawi O, Chatterjee R, Hwang D, Huang Y et al (2003) Imaging human mesolimbic dopamine transmission with positron emission tomography. Part II: amphetamine-induced dopamine release in the functional subdivisions of the striatum. J Cereb Blood Flow Metab 23:285-300. https://doi. org/10.1097/01.WCB.0000048520.34839.1A

Mintun MA, Raichle ME, Kilbourn MR, Wooten GF, Welch MJ (1984) A quantitative model for the in vivo assessment of drug binding sites with positron emission tomography. Ann Neurol 15(3):217227. https://doi.org/10.1002/ana.410150302

Mukherjee J, Shi B, Christian BT, Chattopadhyay S, Narayanan TK (2004) ${ }^{11} \mathrm{C}$-Fallypride: radiosynthesis and preliminary evaluation of a novel dopamine $\mathrm{D} 2 / \mathrm{D} 3$ receptor PET radiotracer in nonhuman primate brain. Bioorg Med Chem 12(1):95-102. https:// doi.org/10.1016/j.bmc.2003.10.020

Nevalainen N, Riklund K, Andersson M, Axelsson J, Ögren M, Lövdén M, Lindenberger U, Bäckman L, Nyberg L (2015) COBRA: a prospective multimodal imaging study of dopamine, brain structure and function, and cognition. Brain Res 1612:83-103. https://doi. org/10.1016/j.brainres.2014.09.010

Papenberg G, Lindenberger U, Bäckman L (2015) Aging-related magnification of genetic effects on cognitive and brain integrity. Trends Cogn Sci 19(9):506-514. https://doi.org/10.1016/j. tics.2015.06.008

Raz N, Lindenberger U, Rodrigue KM, Kennedy KM, Head D, Williamson A, Dahle C, Gerstorf D, Acker JD (2005) Regional brain changes in aging healthy adults: general trends, individual differences and modifiers. Cereb Cortex 15(11):1676-1689. https://doi. org/10.1093/cercor/bhi044

Razifar P, Lubberink M, Schneider H, Langstrom B, Bengtsson E, Bergstrom M (2005) Non-isotropic noise correlation in PET data reconstructed by FBP but not by OSEM demonstrated using auto-correlation function. BMC Med Imaging 5(1):3. https://doi. org/10.1186/1471-2342-5-3

Rieckmann A, Karlsson S, Karlsson P, Brehmer Y, Fischer H, Farde L, Nyberg L, Bäckman L (2011) Dopamine D1 receptor associations within and between dopaminergic pathways in younger and elderly adults: links to cognitive performance. Cereb Cortex 21(9):2023-2032. https://doi.org/10.1093/cercor/bhq266

Robertson CL, Ishibashi K, Chudzynski J, Mooney LJ, Rawson RA, Dolezal BA, Cooper CB, Brown AK, Mandelkern MA, London ED (2015) Effect of exercise training on striatal dopamine D2/ D3 receptors in methamphetamine users during behavioral treatment. Neuropsychopharmacology 41(6):1629-1636. https://doi. org/10.1038/npp.2015.331

Seaman KL, Smith CT, Juarez EJ, Dang LC, Castrellon JJ, Burgess LL, San Juan MD, Kundzicz PM, Cowan RL, Zald DH,
Samanez-Larkin G (2019) Differential regional decline in dopamine receptor availability across adulthood: linear and nonlinear effects of age. Hum Brain Mapp 40:3125-3138. https://doi. org $/ 10.1002 / \mathrm{hbm} .24585$

Slifstein M, Laruelle M (2000) Effects of statistical noise on graphic analysis of PET neuroreceptor studies. J Nucl Med 41(12):2083-2088

Tabachnick BG, Fidell LS (2006) Using multivariate statistics, 5th edn. Allyn Camp; Bacon Inc., Needham Heights

Trifilieff P, Martinez D (2014) Cocaine: mechanism and effects in the human brain, chapter 5. In: Madras B, Kuhar M (eds) The effects of drug abuse on the human nervous system. Academic Press, Boston, pp 103-133. https://doi.org/10.1016/B978-0-12-41867 9-8.00005-8

Tziortzi AC, Haber SN, Searle GE, Tsoumpas C, Long CJ, Shotbolt P, Douaud G et al (2014) Connectivity-based functional analysis of dopamine release in the striatum using diffusion-weighted MRI and positron emission tomography. Cereb Cortex 24(5):11651177. https://doi.org/10.1093/cercor/bhs397

van Velden FHP, Kloet RW, van Berckel BNM, Lammertsma AA, Boellaard R (2009) Accuracy of 3-dimensional reconstruction algorithms for the high-resolution research tomograph. J Nucl Med 50(1):72-80. https://doi.org/10.2967/jnumed.108.052985

Varga J, Szabo Z (2002) Modified regression model for the Logan plot. J Cereb Blood Flow Metab 22(2):240-244. https://doi. org/10.1097/00004647-200202000-00012

Volkow ND, Tomasi D, Wang G-J, Telang F, Fowler JS, Wang RL, Logan J, Wong C, Jayne M, Swanson JM (2009) Hyperstimulation of striatal D2 receptors with sleep deprivation: implications for cognitive impairment. NeuroImage 45(4):1232-1240. https://doi. org/10.1016/j.neuroimage.2009.01.003

Walker MD, Asselin M-C, Julyan PJ, Feldmann M, Talbot PS, Jones T, Matthews JC (2011) Bias in iterative reconstruction of lowstatistics PET data: benefits of a resolution model. Phys Med Biol 56(4):931-949. https://doi.org/10.1088/0031-9155/56/4/004

Wallsten E, Axelsson J, Sundstrom T, Riklund K, Larsson A (2013) Subcentimeter tumor lesion delineation for high-resolution ${ }^{18} \mathrm{~F}$ FDG PET images: optimizing correction for partial-volume effects. J Nucl Med Technol 41(2):85-91. https://doi.org/10.2967/ jnmt.112.117234

Zald DH, Woodward ND, Cowan RL, Riccardi P, Sib Ansari M, Baldwin RM, Cowan RL et al (2010) The interrelationship of dopamine D2-like receptor availability in striatal and extrastriatal brain regions in healthy humans: a principal component analysis of $\left[{ }^{18} \mathrm{~F}\right]$ fallypride binding. NeuroImage 51(1):53-62. https://doi. org/10.1016/j.neuroimage.2010.02.006

Publisher's Note Springer Nature remains neutral with regard to jurisdictional claims in published maps and institutional affiliations. 